\title{
Política, don y hospitalidad en el pensamiento de Jacques Derrida
}

Politics, gift and hospitality in Jacques Derrida's thought

\author{
Ana Paula Penchaszadeh
}

Universidad de Buenos Aires

Resumen. Derrida muestra con agudeza el conjunto de paradojas que es preciso experimentar para exponer la política a su límite, es decir, a su (im)posibilidad. Pero, ¿alberga el concepto de hospitalidad-don algún tipo de esperanza para pensar y concebir una política diferente? ¿Abre la teoría derrideana algún espacio para la libertad, a partir de la denuncia de la estructura sacrificial comprometida en toda identidad? Como se mostrará a lo largo de este trabajo, una respuesta que haga justicia al pensamiento derrideano sólo puede decir «sí y no» al mismo tiempo, moviéndose alternadamente en el terreno de lo posible y de lo imposible.

Palabras clave: Derrida, hospitalidad, don, política.
AbSTRACT. Derrida wittingly shows the set of paradoxes that is necessary to experiment in order to expose the politics to its limit, that is to say, to its (im)possibility. But, does the concept of hospitality-gift gives some type of hope for thinking and conceiving a different policy/politics? Does the Derridean theory open some space for freedom, from the condemnation of the sacrificial structure embedded in all identity? As it will be shown throughout this paper, an answer that makes justice to the Derridean thought can only say «yes and no» at the same time, alternating itself in the land of the possible and of the impossible.

Key words: Derrida, hospitality, gift, politics.

«(...) el anfitrión que recibe (host), el que acoge al huésped invitado o recibido (guest), el anfitrión que acoge, que se cree propietario de los lugares, es en verdad un huésped recibido en su propia casa. Recibe la hospitalidad que ofrece en su propia casa, la recibe de su propia casa - que en el fondo no le pertenece. El anfitrión como host es un guest. La morada se abre a sí misma, a su "esencia" sin esencia, como "tierra de asilo". El que acoge es primeramente acogido en su casa. El que invita es invitado por su invitado. El que recibe es recibido, recibe la hospitalidad en lo que tiene por casa propia, incluso, sobre su propia tierra, según la ley que recordaba asimismo Rosenzweig. Éste subrayaba esa desposesión originaria, la sustracción que, expropiando al "propietario" de su propio mismo, y el ipse de su ipseidad, hace de su en-casa un lugar o una locación de paso».

Jacques Derrida, Adiós a Emmanuel Lévinas.

Este trabajo debe comenzar con una de las grandes preguntas que acechan como una sombra la obra derrideana, ¿puede sacrificarse el sacrificio?, ${ }^{1}$ pues de la 
respuesta a esta pregunta depende la posibilidad de correr el eje de la hostilidad (fundamento moderno de lo político) hacia la hospitalidad. Pero jamás se encontrará una respuesta clara y transparente a esta pregunta, ni allá ni acá, pues lo que ella pone en juego es la identidad: sólo puede haber sujeto, en el sentido restringido y pleno del término - es decir, la referencia a una instancia, a una morada, a través de la cual se volverían «posibles» el derecho, la política, la economía, la cultura y la moral, es decir, el principio de calculabilidad-, ahí donde éste sacrifica al otro, se lo come y lo incorpora. Derrida denuncia la existencia de una estructura sacrificial ${ }^{2}$ en el orden carno-falogocéntrico de nuestras sociedades, alojada no sólo en el ámbito político y jurídico (se puede llegar a conceder sin gran discusión la existencia de un vínculo productivo entre hostilidad, sacrificio, política y ley), sino también en ámbito de la ética y la moral.

Para Derrida el problema del quién se encuentra inevitablemente unido al del sacrificio: «Hay que comer» ${ }^{3}$ equivale a decir que es inevitable sacrificar al otro con otros, siendo ésta una de las formas de la «ley de hospitalidad infinita». Habrá que insistir, también desde el comienzo, en el vínculo profundo y extraño tejido por este autor, sin retorno posible, entre política y psicoanálisis: fin de la transparencia a sí del sujeto que, sin embargo, y pese a su «puesta en cuestión», deberá seguir respondiendo, decidiendo, matando e incorporando al otro (que no es el prójimo/próximo, sino el radicalmente otro con el cual no se puede «contar»), es decir, que seguirá siendo interpelado por la pregunta ¿quién?

Para Derrida, el sujeto recuperado y resituado desde la renuncia a la búsqueda de una identidad originaria (es decir, atravesado por el problema de la huella y de la différance), ese sujeto como ficción convenida que debe preguntarse cada vez por el sufrimiento del otro, es una instancia que sólo puede aprehenderse a sí misma como alteridad, es decir, a partir de la experiencia de una heteronomía radical (de una no-coincidencia consigo mismo). El otro para Derrida resiste a toda subjetivación sometiendo al sujeto a la experiencia de una exapropiación constante y a la imposibilidad de cerrarse sobre sí mismo: no es posible preguntarse a posteriori qué hacer con el otro, pues lo que supuestamente se es dependerá de una respuesta a él/ella/aquél/éste/ésta que es previa a toda conciencia de sí.

«A lo que acabamos de nombrar (nombre propio en exapropiación, firma o afirmación sin firmeza, huella, différance de sí, destinerrancia, etc.), añadiría aquello que queda a la vez requerido por la definición del sujeto clásico y por sus últimos motivos no-clásicos, a saber, una cierta responsabilidad. La singularidad del "quién" no consiste en la individualidad de una cosa idéntica a sí misma, no es un átomo. Ella se disloca o se divide al reunirse para responder al otro, cuya llamada precede, por decirlo así, a su propia identificación consigo misma, porque a esta llamada no puedo sino responder, haber respondido, incluso si creo responderle "no".»" ${ }^{4}$

Derrida busca deconstruir toda la metafísica de la presencia, es decir, la autoridad del ente presente, comenzando por el sujeto mismo, para extender el concepto de responsabilidad misma hacia todo aquello que hasta ahora se encontraba por fuera de la humanidad. ${ }^{5}$ De esta forma, el otro como radicalmente otro sólo aparecerá desapareciendo, es decir, resistiéndose a la incorporación como otro. Es preciso cuestionar el sentido común que ha vertebrado hasta ahora la reflexión acerca de lo propio, del deber y de la responsabilidad, para hacer lugar a todos aquellos vivientes que sufren y cuyos gritos y aullidos se hacen sentir, hablen o no. No se podrá dejar librado ningún lugar para un «matar no-criminal», 
debiéndose correr el eje del sujeto responsable de sí, hacia el «sujeto responsable del otro antes de serlo de él mismo como "yo"». ${ }^{6}$ La máxima derrideana reza: «No expondrás a la muerte al viviente en general, no harás lo harás sufrir, lo comerás ni un poquito». ${ }^{7}$ Es decir, va más allá del humanismo que (incluso en sus versiones heideggeriana y lévinasiana) se habría detenido en los próximos desentendiéndose de los radicalmente otros.

En este trabajo se aborda el problema del don, a primera vista, de un tipo de intercambio entre personas que se dan a sí mismas y a los otros dando cosas. A primera vista, y sólo a primera vista, el vínculo consigo mismo y con el otro se encontrará dado bajo la forma de un don entendido como intercambio. El sujeto se muestra descentrado de sí mismo, necesitando de la refracción de su propia imagen en los otros para afirmarse y darse a sí mismo una identidad: se reconoce que la identidad es «relacional» y que no hay «sujetos» sino procesos de «subjetivación». Se expone así, en la primera parte de este escrito, a un conjunto de autores que sigue la línea maussoniana y estableciendo un vínculo estrecho entre don, identidad y reconocimiento. Pero esta primera perspectiva, antropológico-social, se ve desbordada por la lectura del don que propone Derrida, pues tiende a reducir el problema del don a los términos del cálculo, de la cuenta, de la devolución y del intercambio simbólico, presuponiendo la existencia de sujetos que pueden/deben reconocerse unos a otros (es decir, ser capaces de compartir y de reconocerse a partir de un orden ético). El don, sin embargo, como acontecimiento, no podrá nunca reducirse para Derrida a su fenómeno (a su hacerse presente). Como figura al mismo tiempo de lo posible y lo imposible, el don encierra el problema de la identidad, pues ella siempre será un presente que nos hablará de un tiempo y de cierta espacialidad (como aquello que no puede darse por definición) y de un regalo-don atravesado/mediado por el orden de lo simbólico (pues, se pueden dar cosas, se puede concebir un orden simbólico con ciertas fronteras, mas la dimensión de la identidad como don se encontrará sustraída y diseminada en su sentido siendo posible resignificarla infinitamente).

Derrida muestra con agudeza el conjunto de paradojas que es preciso experimentar para exponer la política a su límite, es decir, a su imposibilidad misma. Pero ¿qué tipo de esperanzas alberga el concepto de hospitalidad-don para pensar y concebir una política diferente? ¿Abre la teoría derrideana algún espacio para una libertad a partir de la denuncia de la estructura sacrificial? ¿Qué efectos políticos puede tener la deconstrucción de las oposiciones políticas y de fronteras tranquilizadoras para una definición del mundo en clave hospitalaria?

\section{Política, economía y filosofía}

«El problema con el que se va a encontrar usted, es que Derrida, a diferencia de una autora como Arendt, no es un pensador de la política». Esta sentencia fue pronunciada por Miguel Abensour, en una entrevista que le hiciera en Paris en la primavera de 2006, y quedó revoloteando largo tiempo sobre este trabajo. Según este autor, Arendt habría logrado reexaminar críticamente la tradición filosófico-política, corriendo el eje del platonismo (origen de la hostilidad filosófica hacia la política) hacia una deconstrucción del campo político a partir de la aceptación de su anarquía constitutiva y de la acción como fundamento de la plural condición humana. Por un lado, Arendt habría recuperado la especificidad de la política, como ámbito de la acción - contingente y singular-, en contrapo- 
sición con el ámbito del saber y la filosofía (retomando la distinción aristotélica entre saber teórico y práctico); $y$, por otro lado, habría distinguido la «fabricación» y la «labor» - la construcción del mundo y la reproducción de la vida-, del hacer de la polis definido como acción (distinción también aristotélica).

Pero ¿cómo se relacionan Arendt y Derrida? Y, yendo un poco más lejos, ¿qué relevancia tienen los problemas arrojados por la teoría derrideana para un nuevo pensar de la política? Contestando a la primera pregunta: si el pensamiento arendtiano es una suerte de paradigma de lo que el pensamiento político es, habría que preguntarse cómo se manifiesta en Derrida la especificidad de lo político; en especial, si es un ámbito diferente o diferenciable de lo filosófico y lo económico. En respuesta a la segunda pregunta: la teoría derrideana resulta fundamental para el pensamiento político porque no sólo permite comprender la productividad del otro para la construcción de la diferencia/identidad (es decir, de la estructura sacrificial de nuestras sociedades), sino que hace posible una desconstrucción/desnaturalización de ésta en nombre de la hospitalidad (no sólo permite localizar la estructura sacrificial sino también reconstruirla y desnaturalizarla para dar lugar al otro).

Comenzando con el tema más espinoso, el vínculo entre filosofía y política, habría que decir, antes que nada, que la filosofía para Derrida no es ni el lugar de la verdad, ni el de la visibilidad. Aun cuando en muchos textos «vuelve a Platón» - llegando incluso a sostener que es el gran referente intelectual de la deuda occidental-, lo retoma en sus aspectos más oscuros, ahí donde se hace imposible una superación dialéctica, donde se confunden los términos prodigiosamente separados en otras etapas. Fiel a su herencia nietszcheana, desnaturaliza y deconstru- ye toda la lógica conceptual sobre la cual pretende alzarse la verdad. Pero, aun cuando resueltamente destrona la filosofía obligándola a aceptar en su seno las «verdades» de la literatura, del psicoanálisis, entre otras, Derrida se ve a sí mismo, en tanto filósofo, como un heredero del proyecto de la Ilustración; un heredero muy particular que pretende realizar una labor hipercrítica de cada uno de los pilares sobre los cuales se ha sostenido como tradición (opone lo racional a lo razonable, lo posible a lo imposible, el evolucionismo al retorno infinito de lo reprimido y a la deuda infinita, el progreso a la idea de pervertibilidad/perfectibilidad, la democracia como proyecto a la democracia como promesa, la autonomía a la heteronomía).

Para Derrida la política y la filosofía se interpelan mutuamente. Cada una de ellas se encuentra constituida por dos dimensiones heterogéneas entre sí que las empujan a ser, cada vez, algo distinto de lo que son. Tanto la política como la filosofía vendrían a representar, la primera bajo el imperio del ethos, la segunda bajo el del logos, el intento de hacer calculable lo incalculable, de dar coherencia a un mundo por definición caótico y sin sentido. En tanto «intentos» de aprehender algo por definición inasible (el enigma encriptado de la singularidad), en cada una de sus construcciones se oculta como una herida/huella aquello que se reprime para dar transparencia e inteligibilidad al mundo: el otro (que, en Derrida, representa todo aquello que no puede ser previsto, calculado, superado, apresado, extirpado). Así, la filosofía y la política vendrían a ser ámbitos en los que se delinea lo posible a partir de determinadas reglas y ciertos conjuntos de oposiciones; pero, al mismo tiempo, son ámbitos que albergan lo imposible y lo incalculable, es decir, la huella y la differánce de la alteridad. De ahí que la filosofía deba ser 
pensada desde lo razonable (no ya desde lo racional, del logos) y que algo fundamental de la política se manifieste, para Derrida, cuando se suspende el orden ético, poniéndose en cuestión las condiciones mismas que lo hacen posible.

Acá conviene retomar nuestra segunda cuestión: ¿existe en Derrida una división clara de la esfera de política y la esfera económica? ¿Otorga algún tipo de especificidad a la primera con respecto a la segunda? Como en la anterior cuestión, la respuesta es sí y no. Si tomamos la política en sentido amplio y a partir del valor de la incalculabilidad, claramente la política sería algo distinto de lo económico. Pero si la concebimos como el intento de hacer calculable lo incalculable, entonces, la política sería prácticamente lo mismo que la economía. Cuando Derrida critica la política condicional o «real» lo hace siempre en nombre de una subordinación de ésta a lo económico, es decir, a la lógica del cálculo. Tal vez uno de los puntos más importantes para poder aprehender la complejidad que encierra la política y su vínculo con lo económico en Derrida, es la cuestión del don y una de sus formas específicas, la hospitalidad, cuestión que constituye el eje del presente capítulo.

Derrida plantea la convergencia de, al menos, dos formas heterogéneas e irreductibles de concebir el don, la identidad y la hospitalidad: una antropológico-sociológica, estrechamente vinculada con la lógica del reconocimiento -que da sustento a una constatación de la productividad de la lógica sacrificial del otro en consonancia con una lectura «realista» de la política; y una filosófica (cuasi-trascendental), basada fundamentalmente en la teoría de Derrida, cuyo eje es la deconstrucción de la dialéctica identidad/ diferencia a partir de un deber incondicional frente al otro. A continuación se exponen de forma detallada cada una de estas perspectivas y se interrogan los puntos en los cuales se hace posible/deseable un diálogo entre ellas.

La hospitalidad como don se encuentra en un espacio de cruce de lo político, lo económico, lo social, lo ético y, también, de lo filosófico: la hospitalidad conlleva siempre un deber, en este sentido, se conecta no sólo con una ontología jurídica, con un tiempo (una temporalidad) y un lugar (topos), sino también con cierta deontología justiciera. De ahí que haya que preguntarse: ¿por qué la hospitalidad, como don, se limita donde quiera que existe?

\section{Don e intercambio. Mauss y Benveniste}

El Ensayo sobre el Don escrito por Marcel Mauss en 1923 es la referencia obligada de todas las reflexiones sobre la cuestión del don y de una de sus formas específicas: la hospitalidad. ¿Por qué este ensayo se ha constituido en uno de los textos más discutidos de la antropología moderna? La respuesta en términos generales a esta pregunta es que en él se describe una forma de relación con el otro, no basada ni en el mero interés ni en la utilidad $^{8}$ (una de las «rocas» de nuestras sociedades), que permite concebir un vínculo con el otro que escaparía al «frío cálculo». ${ }^{9}$ Mauss se detiene en un tipo de circulación de las cosas, los bienes y las personas, cuyo eje no es la acumulación sino el gasto, y cuyo fundamento es el reconocimiento del otro y de sí mismo en el acto de dar, recibir y devolver. De ahí que la mayor parte de los autores que, en el marco de las ciencias sociales y humanas, siguen la línea trazada por Mauss encuentren un fuerte vínculo entre la estructura circular del intercambio del don y la lógica de la estima de sí y el reconocimiento. 10

«El potlatch, la distribución de bienes, es el acto fundamental del "reconocimiento" mi- 
litar, jurídico, económico, religioso, en todos los sentidos de la palabra. Reconociendo al jefe o a su hijo devenimos "reconocibles".»" ${ }^{11}$

Mauss remarca que el don siempre implica una obligación de aceptación y de devolución/restitución de lo dado; el eje de su investigación es la lógica circular que se pone en marcha con el acto de dar como obligación que conlleva en sí misma las obligaciones de recibir y de devolver lo recibido. En estos procesos de intercambio de dones, colectividades bajo la forma de clanes, tribus y familias, se enfrentan y se oponen manifestándose respecto entre sí, ${ }^{12}$ reconociéndose en el sentido más profundo del término. Las obligaciones de dar, recibir y devolver tienen como fundamento un reconocimiento que orienta a los que participan de ellas hacia la paz: el que no cumple con alguna de estas tres obligaciones «pierde su cara», su lugar, e incluso deviene esclavo del otro. La lógica circular del don-contra-don implica la salida del caos y la entrada de lo social en una temporalización del vínculo, la inscripción del vínculo con el otro en un tiempo diferido ${ }^{13}$ que ya no sería infinito sino finito, basado en el crédito y en la fe, en un prometerse al otro más allá del presente.

«Las sociedades han progresado en la medida en que ellas mismas, sus subgrupos y sus individuos han sabido estabilizar sus relaciones, dar, recibir, y finalmente, devolver. Para comenzar fue necesario primero saber deponer las armas.») ${ }^{14}$

Mauss también define una dimensión agonística del don que supone un dar sin retorno. Representado por algunas formas del potlatch, la excepción de la obligación de devolver se produce cuando el don consiste en pura destrucción. El don es sacrificial porque se ofrece a los espíritus intentando así afirmar la superioridad absoluta de aquél que da sin retribución (Mauss, 2004: 212): «el consumo y la destrucción no tienen límites. En ciertos potlatch se debe gastar todo lo que se tiene y no guardar nada. El más rico es el más gastador. El status político se obtiene a través de la "guerra de propiedad". (...) Todo es concebido como si fuera una lucha de riqueza» (Mauss, 2004: 200). Seguimos aquí en la lógica del reconocimiento sólo que, en este caso particular, se manifiesta como una «lucha» (no una guerra o, por lo menos, no directamente) que puede entrañar grandes sacrificios en pos del reconocimiento de una superioridad ${ }^{15}$ y el establecimiento de una jerarquía. He aquí uno de los puntos más discutidos y retomados de este texto, pues permite conectar el problema del don, el sacrificio, lo sagrado y la soberanía.

«[Un jefe] no conserva su autoridad sobre su tribu y su pueblo, sobre su familia, no mantiene su rango entre los jefes -nacionalmente e internacionalmente - mas que si prueba que lo asedian y favorecen espíritus y la fortuna, que se encuentra poseído por ella y que la posee; y sólo puede probar esta fortuna gastándola, distribuyéndola, humillando a los otros, y poniéndolos a la "sombra de su nombre"» 16

La hospitalidad como don, tal como es concebida Mauss y retomada por Benveniste, se inscribe en la lógica económica de la reciprocidad, del intercambio, del círculo de dones entre distintas comunidades. En el capítulo «Don e intercambio», luego de haber asociado estos dos términos remarcando su carácter desinteresado ${ }^{17}$ (a diferencia de los de compra-venta), Benveniste plantea lo siguiente refiriéndose a la tradición griega: «No se trata solamente de un presente, de un don desinteresado; es un don en tanto que prestación contractual, impuesta por las obligaciones de un pacto, de una alianza, de una amistad, de una hospitalidad: obligación del xeînos (del hôte), de los sujetos para con un rey o el dios, o mismo una prestación producto de una alianza». ${ }^{18}$ 
Benveniste, asimismo, cita a Mauss planteando la existencia del potlatch en ciertas instituciones indo-europeas: «Es necesario mostrarse pródigo con sus bienes para hacer ver que no se les da importancia, para humillar a sus rivales por el despilfarro instantáneo de riquezas acumuladas. Un hombre conquista y mantiene su rango si sobrepasa a sus rivales en este gasto desenfrenado. El potlatch es una provocación a los otros para que gasten a su turno; los competidores hacen un gasto superior, de ahí el circuito de riquezas acumuladas y repartidas por el prestigio de unos y la felicidad de otros, como Mauss lo ha bien mostrado.» ${ }^{19} \mathrm{Si}$ bien Benveniste insiste en el carácter secundario de la rivalidad en las nociones indoeuropeas del don, plantea que la reciprocidad y la emulación son parte constitutiva de éstas, en especial en una de sus manifestaciones más importantes: la hospitalidad. ${ }^{20}$

Para Benveniste la hospitalidad se da siempre dentro de ciertos límites y en base a una institucionalidad; es un recibir condicionado por un ethos, subordinado a la lógica del derecho. Esta definición de la hospitalidad nos reenvía a la cuestión de la soberanía y a la constitución del «nosotros frente a los otros» que tiene su punto clave en la dialéctica amigo-enemigo y en la posibilidad de diferenciación de un adentro-afuera.

«(...) el extranjero es necesariamente un enemigo- y, correlativamente, el enemigo es necesariamente un extranjero. Puesto que siempre aquel que ha nacido por fuera de la comunidad es a priori un enemigo, un compromiso mutuo es necesario para establecer, entre él EGO, relaciones de hospitalidad inconcebibles al interior mismo de la comunidad. Esta dialéctica "amigo-enemigo", como se ha mostrado previamente, juega un rol central en la noción de phílos: un enemigo, aquél a quien se combate, puede devenir temporalmente phílos, por el efecto de una convención celebrada según los ritos y los compromisos consagrados.» 21
El extranjero, como bien muestra Benveniste, es aquel en el que confluyen las figuras del hospes - aquel que puede ser recibido por el dueño «maître» de casa, con toda la filiación que encierra este «recibimiento» (huésped/anfitrión) con la cuestión de la potestad, de la autoridad y de la soberanía - y del hostis — el enemigo que pone en marcha los mecanismos de compensación por los cuales se establece la noción de «comunidad» como conjunto de hombres unidos por ciertos lazos de reciprocidad-. ${ }^{22}$ Ahora bien, el xénos (aquel que se encuentra ligado y reconocido por otros hombres a través de pactos y obligaciones propios de la pertenencia a un linaje, a una xenia), no es el héteros (el bárbaro, el radicalmente otro). El derecho/deber de hospitalidad que compromete a una casa, se encuentra inscrito en un ethos ${ }^{23}$. Pero, cabe preguntarse, ¿qué sucede con aquellos cuya negación es «constitutiva» de la propia identidad? En especial, ¿cómo se puede salir de la estructura sacrificial del otro (del héteros, el radicalmente otro) cuando de ella depende la construcción singular de una ética, de una morada, de un espacio desde el cual recibir?

Dentro de esta perspectiva antropológico-sociológica del don existe, en la actualidad, una línea de reflexión denominada la teoría del reconocimiento. La Revue du Mauss, que nuclea a un conjunto de investigadores de las ciencias sociales y humanas autodenominado antiutilitarista, es un buen ejemplo de ello. Poniendo el énfasis en los aspectos «constructivos» del don para el reconocimiento/identidad, en ella se sostiene que éste es un «operador moral y político por excelencia, que toma plenamente sentido como medio performativo y simbólico para el reconocimiento público y privado». ${ }^{24}$ En la presentación del número 23 de esta revista, titulado De la reconnaissance. Don, identité et estime de soi, su 
director Caillé se pregunta retóricamente: «¿Decir que el don es el medio por el cual se opera el reconocimiento público entre adversarios es radicalmente distinto de afirmar que el don es el operador que forma políticamente una sociedad transformando a los enemigos en amigos?» 25 Para esta corriente neo-maussoniana existe un vínculo muy estrecho entre el sistema de don-contra-don y la lógica del reconocimiento: el "valor del sujeto», su reconocimiento, se realizaría con la mediación del don en el acto de dar-recibir-devolver. ${ }^{26}$ Tanto en sus aspectos cooperativos, como en sus aspectos agonísticos, el énfasis se encuentra puesto en la capacidad del don para arrancar a los hombres del mundo de la guerra y colocarlos en el de la lucha - en el orden ético y político, en una temporalidad.

\section{Don infinito y hospitalidad}

«Aunque todas las antropologías, e incluso las metafísicas del don, con toda razón hayan tratado conjuntamente, como un sistema, el don y la deuda, el don y el ciclo de la restitución, el don y el préstamo, el don y el crédito, el don y el contra-don, nosotros desistimos aquí, de forma enérgica y tajante, de esta tradición. Es decir, de la tradición misma. Como punto de partida nos situaremos en la disociación, en la cegadora evidencia de este otro axioma: no hay don, si lo hay, sino en aquello que interrumpe el sistema o también el símbolo, sino en una partición sin retorno y sin repartición sin el ser-consigo-mismo del don-contra-don.»

Jacques Derrida, Dar el tiempo. I. La moneda falsa

En Dar el tiempo y Dar la muerte Derrida expone por qué el don debe ser pensado más allá de la lógica del cálculo económico, rompiendo así con la lectura maussoniana tradicional, que lo reenvía al círculo del don-contra-don y el inter- cambio. La idea de economía misma es descompuesta por este autor en sus dos fuentes etimológicas, oikos y nómos, interpelando el orden y la ley (nómos) «natural» de la casa y la familia (oikos). El resultado de esta descomposición, de este hiato que anuncia el don «sin presente», es la imposibilidad de apelar a una «buena medida» para diferenciar la economía (el intercambio medido por la necesidad de la casa-familia) de la crematística (que ha perdido toda referencia a la necesidad, disparándose en gasto desenfrenado y lujo).

«En cuanto hay signo monetario y, sobre todo, signo, es decir, differánce y crédito, el oikos se abre y no puede dominar su límite. En el umbral de sí misma, la familia no conoce ya sus confines. Es, a la vez, su ruina originaria y la ventura de todas las hospitalidades. (...) es la ventura del don mismo. La ventura del acontecimiento. Ciertamente, nada puede pasar sin familia y sin economía, pero nada puede pasar tampoco en familia, en familia, es decir, en la mullida clausura, por lo demás inimaginable, de la economía restringida, absolutamente restringida y que carece del más mínimo vértigo crematístico.» ${ }^{27}$

Derrida se pregunta si es pensable un don que vaya más allá de su fenómeno (que, paradójicamente, es su negación). El don debería ser (si lo hay, dice Derrida) alogos (no reducible a la razón/discurso/relación/cuenta) y atopos (no estando ni en su sitio ni en su lugar, es lo extraordinario, lo insólito, lo extraño, lo extravagante, lo absurdo, lo loco); ${ }^{28}$ debería mantener una extrañeza respecto de lo económico, con la casa y la ley, marcando cada vez el comienzo del círculo. Si bien el don es lo imposible mismo, que desgarra cada vez el círculo y el tiempo como un primer motor, ello no implica que sea lo impensable. La cuestión del don abre la puerta a una de las cuestiones más interesantes de la teoría derrideana en términos políticos: la cuestión del acontecimiento y lo incalculable, que no 
es otra cosa que la irrupción del (lo) otro; $\mathrm{y}$, en este horizonte también, la cuestión de la ilusión trascendental que atraviesa toda su teoría: "Vamos a dedicarnos al esfuerzo de pensar o repensar una especie de ilusión trascendental del don. Y vamos a (compro)meternos en dicho esfuerzo. Porque una teoría del don es, por esencia, insuficiente para pensar el don.» 29

Pero ¿por qué una teoría del don es insuficiente para pensar el don? Según Derrida, la descripción maussoniana del don, a partir de su hacerse «presente», no debe confundirse con el don mismo, ${ }^{30}$ como acontecimiento incalculable que rompe con la reciprocidad, la devolución y el círculo «ritual de la deuda» fundamento de la «estructura simbólica sacrificial o económica» ${ }^{31}$. Para Derrida se trata de ir más allá incluso del antiutilitarismo, ${ }^{32}$ de renunciar a la lógica del reconocimiento según la cual el don es fuente constitutiva de sujetos idénticos e identificables (Derrida, 1995: 32). Esta cuestión es de vital importancia para la presente indagación, pues representa el punto en el que se hace pensable un desbordamiento de la lógica sacrificial que estructura todo el problema de la identidad en la ontoteología occidental: hasta ahora el don, la hospitalidad como don, sólo ha sido pensada como aquello que «pone en relación» constituyendo a determinados sujetos. De ahí que no se pueda renunciar al sacrificio del radicalmente otro ahí donde su diferencia se reconoce como fundamental para la propia identidad.

«Supongamos que alguien quiera o desee dar a alguien. Lo decimos dentro de nuestra lógica y de nuestra lengua: alguien quiere o desea dar, alguien tiene la intención-de-dar algo a alguien. La complejidad de la fórmula ya resulta temible. Supone un sujeto y un verbo, un sujeto constituido que también puede ser colectivo - por ejemplo, un grupo, una comunidad, una nación, un clan, una tribu, en cualquier caso un sujeto idéntico a sí mismo, consciente de su identidad y que a través del gesto del don, trata de constituir su propia unidad y de hacer que se reconozca, justamente, su propia identidad para que ésta vuelva a él, para reapropiársela: como propiedad suya.» (Derrida, 1995: 20)

Para Derrida en la medida en que no se pueda pensar el don más allá de la lógica del reconocimiento y de la deuda, no se podrá salir de la lógica de la identidad que, a su vez, es la de la dominación y sacrificio del otro. ${ }^{33}$ Lo interesante de pensar otra forma del don, más allá de su fenómeno es que se corre el eje de la cuestión del deseo de identidad, a la angustia de la singularidad; el don, incluso en su forma más radical, agonística, «puramente destructiva», se sostiene sobre una economía del reconocimiento, de la deuda y de la autogratificación narcisista; esto implica que todo don, todo presente, se hace con vistas al reconocimiento de la propia identidad.

Pero ¿el don es siempre sacrificial? O, más precisamente, ¿la hospitalidad es siempre sacrificial? Una primera respuesta de Derrida es que no: «El sacrificio siempre se distinguirá del don puro (si lo hay). El sacrificio no propone su ofrenda más que bajo la forma de una destrucción contra la que intercambia, espera o da por hecho un beneficio, a saber, una plusvalía o, al menos, una amortización, una protección y una seguridad.» ${ }^{34}$ Derrida sostiene que existe una «economía sacrificial» o una «dimensión ética del sacrificio», ${ }^{35}$ que funciona como sustento de la identidad. El orden ético une a los semejantes en tanto que son próximos y en tanto comparten un ethos (a partir de una racionalidad práctica que hace posible orientarse en función de determinados valores y principios); la responsabilidad se dirime aquí dentro de lo que Derrida define como la «generalidad ética»: a través de la palabra y el intercambio se produce una fidelidad hacia los «nues- 
tros») que, como contraparte, lleva siempre a una irresponsabilización frente a los otros otros. ${ }^{36}$ Sin embargo, al lado de esta «ética condicional», Derrida erige una ética absoluta, silenciosa y secreta, capaz de asumir la responsabilidad sin intentar apaciguar la absoluta soledad frente a la decisión: es decir, de darse al otro en una absoluta pureza del don. Esta hiper-ética, que se desentiende del cálculo y del círculo del contra-don - afirmación de la más pura singularidad que sólo se da frente a (al don de) la muerte-, no podrá desembarazarse jamás de sus efectos paradójicos asociados al carácter finito que instituye la singularidad:

«El deber absoluto exige que nos conduzcamos de forma irresponsable (perfidia o perjurio) reconociendo, reafirmando, confirmando lo mismo que se sacrifica, a saber: el orden de la ética y de la responsabilidad humanas. En una palabra, la ética debe ser sacrificada en nombre del deber. Es un deber no respetar, por deber, el deber ético.» ${ }^{37}$

Dar (la) muerte, texto en el que Derrida aborda las paradojas de la responsabilidad, sometiendo toda decisión a la indecidibilidad y a la incalculabilidad, aborda el problema del don y de la hospitalidad mostrando cómo no podrán escapar jamás a la lógica sacrificial pues el secreto de la singularidad, de una singularidad responsable, consiste en que sólo se podrá responder al otro matando a otros otros. Se abre así un espacio extraño, trágico y agonal, en el cual las figuras pensables del don infinito y de la hospitalidad incondicional toman en cuenta aquello/aquellos que se excluyen y por el sufrimiento que necesariamente se infringe al otro cada vez que se decide.

«Se trata en efecto de una economía, a saber, de la ley (nomos) del oikos, de la familia y del hogar. Y del espacio que separa o asocia el fuego del hogar familiar con el fuego del holocausto sacrificial. Doble hogar, doble fuego y doble luz: dos formas de amar, de quemar y de ver.» ${ }^{38}$

La gran paradoja que instituye la responsabilidad como una forma de darse al otro, de comprometerse con el otro, de darle asilo y hospitalidad, consiste en que siempre que se responde al otro se traiciona (sacrifica) al mismo tiempo, e irremediablemente, a otro otro. El secreto de la singularidad, que no es otro que el de la mortalidad y la finitud, consiste justamente en la incapacidad de responder a todos al mismo tiempo. De forma que el don es siempre sacrificial, y por lo tanto, sí existe una equivalencia entre don y sacrificio.

«No puedo responder a la llamada, a la petición, a la obligación, ni siquiera al amor de otro, sin sacrificarle otro otro, otros otros. (...) La paradoja, el escándalo, la aporía no son otra cosa que el sacrificio: la exposición del pensamiento conceptual a su límite, a su muerte y finitud. Desde el momento en que estoy en relación con el otro, con la mirada, la petición, el amor, el orden, la llamada del otro, sé que no puedo responderle más que sacrificando la ética, es decir, lo que me obliga a responder también y del mismo modo, en el mismo instante, a todos los otros. Doy (la) muerte, perjuro, para ello no tengo necesidad de alzar el cuchillo sobre mi hijo en la cumbre del Monte Moriah.» ${ }^{39}$

La diferencia entre las formas políticas y culturales particulares reside en cómo se reapropian de esta «economía del sacrificio». La mayoría de las familias, comunidades, sociedades, difieren y organizan el sacrificio hacia el otro 40 para no sacrificarse a sí mismas. ${ }^{41}$ De ahí el lugar endeble y productivo del extranjero, como arcano de la soberanía y la identidad. Ahí donde el problema de la identidad continúa siendo crucial (y siempre lo será, pues no existe una definición de sí que el quién pueda apropiarse de una vez y para siempre) no podrá haber hospitalidad, pues, en el origen so- 
ñado de lo propio estará siempre la productividad de la hostilidad.

Derrida en Dar (el) tiempo trabaja una de las tantas figuras de la otredad: el mendigo. Muchas de las reflexiones en torno a esta figura pueden servir para pensar la del extranjero, en tanto que ambas se definen por su exclusión: «De acuerdo con una estructura análoga a la del pharmakos, a la de la incorporación sin introyección y sin asimilación, la expulsión del mendigo (res)guarda el fuera dentro y garantiza una identidad por la exclusión, con excepción (fors) de una clausura o de una separación interna.» ${ }^{42}$ Así como el extranjero, el mendigo se encuentra inserto en una estructura sacrificial, pero como ya dijimos esto es justamente lo que debería poderse suspender (la justificación de la estructura simbólica del sacrificio para la constitución de la propia identidad).

Ahora bien, ¿de qué sirve pensar algo imposible? Según Derrida, tiene sentido pensar un desbordamiento del círculo por el don, pues ahí donde se cree que hay cálculo y ganancia, se cuela siempre el (lo) otro como exterioridad que pone en marcha el círculo. ${ }^{43} \mathrm{Y}$, en relación con esta idea de desbordamiento y de exterioridad que pone en marcha el círculo mismo, la hospitalidad como don dará siempre más allá del cálculo y de la ley; es un dar que recibe siempre como trasgresión: el otro esperado es en realidad, siempre, singularidad incalculable y acontecimiento que viene a romper con el oikos y el nómos. Cuando Derrida habla de «la mullida clausura» para referirse al ámbito económico o de la familia, del hogar, y de un cierto vértigo crematístico, introduce también una cuestión política fundamental: el otro siempre es disruptivo y marca el comienzo del fin de las propias seguridades.

Se puede decir que existen dos momentos en la concepción derrideana del don. Por un lado, una definición del don más allá de su fenómeno, pura, contenida, principalmente, en Dar (el) tiempo. En este texto Derrida se detiene claramente en un dar como acontecimiento, ${ }^{44}$ exigiendo una pureza absoluta del dar (sin retorno, no-intencional, sujeto al olvido absoluto) y suscribiéndolo así al ámbito de lo imposible. La violencia misma del don, «su impureza constitutiva», ${ }^{45}$ consiste en que el que lo recibe se vuelve presa o esclavo de aquel que lo da en la medida en que no lo puede retribuir (recuperando la afinidad semántica entre regalo y veneno). El don en tanto acontecimiento desgarra la historia pues siempre representa un exceso respecto de toda medida. Derrida lo diferencia de la razón práctica, de la ética y la política que se fundan en la idea de deber, para situarlo en un lugar fuera-de la ley que se sustrae a toda anticipación, problematización o cálculo: en última instancia el lugar del don (si lo hay, diría Derrida) es el lugar del secreto que asedia pero que no se hace presente. Por otro lado, en Dar la muerte, el eje se corre de lo calculable hacia lo incalculable no ya a través de la figura pensable del don puro como acontecimiento, sino a través de las consecuencias del don como acontecimiento. Este segundo aspecto es el que tal vez tenga más relevancia para la presente investigación: pues aun cuando se $d a$ esperando una gratificación económica o simbólica del otro (pensado siempre en el intercambio - la retribución-que supone todo acto de dar, aun el más desmedido), siempre en el acto de dar se cuela el otro, lo otro, lo incalculable. Aun cuando se crea estar seguro dando hospitalidad a un amigo, en realidad siempre con él se introduce lo otro en el seno de la propia familia (del oikos), poniendo en riesgo el orden de casa (nómos). Así toda economía del don en realidad revela que el don siempre es más que su propio fenómeno: 
en tanto don, la hospitalidad, es siempre aventura y acontecimiento, pues no es posible hacer un cálculo del otro, en la medida en que es otro.

Pasamos aquí a contestar la segunda pregunta que diferimos en la introducción: ¿qué vínculo existe entre política y economía en la teoría de Derrida? Para Derrida la ética y la política deben ser pensadas, por justicia hacia el otro como singularidad incalculable, más allá de la lógica del intercambio, de la reciprocidad y del reconocimiento; más allá de la lectura «realista/condicional» de la identidad y la soberanía. La política y la ética siempre se encontrarán referidas a algo que todavía no tuvo lugar, de ahí que Derrida haga posible pensar un plano incondicional, cuasi-trascendental, una hiper-ética e hiper-política y la deconstrucción como hospitalidad incondicional y trágica del radicalmente otro.

La hospitalidad incondicional es un don ofrecido graciosamente que se da más allá del cálculo, como transgresión de la ley; no busca hacer comunidad, da de forma desproporcionada; establece con el otro un vínculo desapropiado, una amistad aneconómica. ${ }^{46}$ Derrida desnaturaliza las fronteras de la distinción de adentro/afuera, amigo/enemigo sobre las cuales se traza la hostipitalidad posible; ésta se encuentra siempre-ya asediada por la incondicionalidad que funda el derecho. El extranjero (conteniendo en sí mismo al xénos/héteros ${ }^{47}$ es una figura particular que atenta, por su forma misma, contra el logos (la ley razonable de la propia-casa). En este sentido, para Derrida la hospitalidad que se ofrece al otro, a su nada, a su muerte, a su ausencia, será siempre por definición parricida; se ejercerá contra el dueño de casa, contra el padre que hace la ley y el orden que se funda en la condicionalidad del derecho y la soberanía. El extranjero, el desconocido anónimo, introduce la sospecha de una heteronomía inerradicable, de una separación dentro del sí-mismo. ${ }^{48} \mathrm{Se}$ lo recibe siempre, se lo sepa o no, fuera de la ley. De ahí que pueda ser tratado como loco o enemigo, pues su presencia, en tanto transgresión, podrá a la ley en el camino de la perversión/perfección al derecho al borrar la frontera entre lo privado y lo público, entre lo inapropiado/able y lo apropiado/able.

La hospitalidad condicional del xénos (de aquel cuya venida es prevista y regulada por el derecho y la ley) se encuentra asediada por la hospitalidad hiperbólica, incalculable, aneconómica, que se ofrece a cualquier/radicalmente otro, al héteros (cuya llegada no puede ser prevista o regulada). De la invitación a la visitación ${ }^{49}$; del don como reciprocidad al don como responsabilidad infinita frente al radicalmente otro, éste es el pasaje que propone Derrida.

La hospitalidad acontece en el reencuentro de dos regímenes contradictorios, heterogéneos, inconmensurables e inseparables (el de la justicia y el derecho). Derrida promueve una suerte areté en ausencia de un justo medio (como ex-ceso de lo cuantificable, del derecho). El problema de la hospitalidad debería colocarse siempre por encima de la dimensión ética. De ahí que Derrida conciba la hospitalidad absoluta como hospitalidad abrahámica; aquella que, al responder al radicalmente otro, suspende, traiciona $\mathrm{y}$, paradójicamente, incorpora y ratifica el orden ético (de la familia, la comunidad, la nación). Justicia que se da sin contar, que se desentiende del principio de equivalencias propio del derecho. Don infinito (como don de muerte) que inaugura el espacio anecónomico de la singularidad y, por lo tanto, una política abierta a la irrupción del otro y sometida al vértigo de la democracia como principio de hospitalidad infinita.

He aquí un pensamiento del don, de la hospitalidad incondicional como don 
infinito, que viene a desarmar un sentido común que asocia rápidamente, diferencia, hostilidad y sacrificio, a partir de una economía del reconocimiento. $\mathrm{He}$ aquí un pensamiento paradojal que pone el énfasis en lo incalculable, en una política en clave hospitalaria abierta al riesgo del acontecimiento y de la democracia como espacio de irrupción de ese/eso otro que no puede ser previsto. El otro, el radicalmente otro, arruina de antemano todo cálculo y re-inscribe a la política en la anarquía (an-arché), marcando así el comienzo y el fin del quién, como instancia de la responsabilidad que, sin embargo, debe seguir respondiendo. He aquí la instancia del quién, nada más y nada menos que el problema de la identidad (del sujeto, de la comunidad, del Estado) desnudado como arcano del don, un don sujeto al olvido absoluto, en cuyas insondables latitudes es posible pensar un desbordamiento de las matrices sacrificiales sobre las cuales se han erigido, hasta ahora, las políticas de la identidad.

\section{NOTAS}

1 Derrida, J., "Hay que comer» o el cálculo del sujeto, entrevista realizada a Jacques Derrida por Jean-Luc Nancy publicada en Revista de los Confines, n. ${ }^{\circ}$ 17, Buenos Aires, 2005, Versión de digital http://www.jacquesderrida.com.ar.

$2 \ll(\ldots)$ el sacrificio es la necesidad, el deseo, la autorización, la justificación de la puesta en muerte, la puesta en muerte como denegación del asesinato. La puesta en muerte del animal, dice esta denegación, no será un asesinato. Y yo enlazaría esta "denegación" a la institución violenta del "quién" como sujeto.» Ibid.

3 Ibid.

${ }^{4}$ Ibid.

5 «La autoridad y la autonomía (porque aún si esta se somete a la ley, esta sujeción es libertad) son, según el esquema del sujeto dominante, más bien concedidas al hombre (homo y vir) que a la mujer, y más bien a la mujer que al animal. Y, bien entendido, más bien al adulto que al niño. La fuerza viril del varón adulto, padre, marido o hermano (el canon de la amistad privilegia el esquema fraternal) corresponde al esquema que domina el concepto de sujeto. Éste no se desea solamente señor y poseedor activo de la naturaleza. En nuestras culturas, él acepta el sacrificio y como de la carne.» (Ibid.)

${ }^{6}$ Ibid.

7 Ibid.

8 «Una parte considerable de nuestra moral y de nuestra vida misma ella misma se basa siempre en esta misma atmósfera del don, de la obligación y de la libertad mezcladas. Afortunadamente, todo no se encuentra clasificado exclusivamente en términos de compra y venta. Las cosas todavía tienen un valor sentimental (...)». Mauss, M. (1950): «Essai sur le don. Forme et raison de l'échange dans les sociétés archaïques» dans Sociologie et antropologie, Paris, PUF, $1950,258$.
9 «Y como constataremos que esta moral y esta economía (del don) funcionan todavía en nuestras sociedades de forma constante y por así decirlo subyacente, como creemos haber encontrado aquí una de las rocas humanas sobre las cuales se han construido nuestras sociedades, podemos deducir algunas conclusiones morales sobre algunos problemas que posan la crisis de nuestro derecho y la crisis de nuestra economía (...)». Ibid. 148.

10 «La economía del intercambio-don es una economía del prestigio que deshace la conceptualización utilitarista en distintos niveles. Primero, es preciso subrayar que ella pone en juego relaciones de tipo afectivo, que se articulan en torno del deseo de reconocimiento y de poder, y que se encuentran por ello teñidas de una irracionalidad funcional. En segundo lugar, ella implica bienes simbólicos más próximos al lujo que a la necesidad. Finalmente, ella se apoya esencialmente sobre fenómenos de gasto, y no de acumulación y de conservación; su carácter no es simplemente improductivo, sino contra-productivo, porque es claramente dispendioso.» Karsenti, B., Marcel Mauss. Le fait social total, Paris, PUF, 1994, 122.

11 Mauss, M., op. cit., 210.

12 Mauss, M., op. cit., 150.

13 Si bien Derrida muestra las contradicciones entre don e intercambio, se detiene en la cuestión fundamental de la temporalización que comienza con cada una de las obligaciones dar-recibir-devolver. Siguiendo la línea de Mauss, Derrida sostiene que a través del intercambio de dones el vínculo entra en una nueva temporalidad basada en el crédito y en el plazo: «el don no es un don, no da sino en la medida en que da (el) tiempo». Derrida, J., Dar el tiempo. I. La moneda falsa, Barcelona Editorial, Paidós, 1995, 47.

14 Mauss, M., op. cit., 278.

15 «La generosidad en realidad es una lucha de poder, un deseo de sometimiento de aquel al cual se 
dona algo. Es la impresión de una forma de poder y prestigio que se manifiesta mediante una guerra de propiedad en la cual se juega el lugar del sujeto. (...) El intercambio a través del don sería la cristalización del vínculo agonístico que liga a los hombres entre ellos: sustituto de la guerra de todos contra todos.» «La guerra de propiedades es una guerra reconducida simbólicamente. Solidaridad paradojal, la violencia subsiste en el seno mismo del intercambio. Dialéctica del amo y el esclavo, lucha a muerte por el reconocimiento. El reconocimiento es el deseo de deseos de ser reconocidos por otros con el solo fin de obtener un valor de superioridad y sometimiento.» Karsenti, B., op. cit., 31-33.

16 Mauss, M., op. cit., 205-206.

17 Acá aparece una de las cuestiones más remarcadas por Derrida: la idea de don interesado destruye la idea misma de don, que, «por definición» debe ser desinteresado.

18 Benveniste, É., Le vocabulaire des institutions indo-européennes. 1. Économie, parenté, société, Paris, Editions de Minuit, 1969, 69. Traducido del francés.

19 Ibid., 76.

20 Ibid.

21 Ibid., 361.

22 «Lo quiera o no, lo sepa o no, la hostilidad testimonia asimismo la hospitalidad: "separación radical", "relación con el otro", "intencionalidad", conciencia de, atención a la palabra o acogida del rostro.» Derrida, J., Adiós a Emmanuel Lévinas. Palabra de acogida, Madrid, Editorial Trotta, 1998, 72.

23 «La hospitalidad es la cultura misma y no meramente una ética entre otras. En tanto que ella afecta al éthos, a saber, a la morada, a la propia casa (chez-soi), a la estancia familiar, así como a la manera de ser, a la manera de vincularse consigo mismo y con los otros, con los suyos o con los extranjeros, la ética es hospitalidad, ella es, de comienzo a fin, coextensiva a la experiencia de la hospitalidad, a la forma en que se la abre o se la limita. Pero por esta misma razón, y porque el ser-sí-mismo en-sí (la ipseidad misma) supone una recepción o una inclusión del otro al que se busca apropiar y controlar, según distintas modalidades de la violencia, es que hay una historia de la hospitalidad, una perversión siempre posible de la Ley de la hospitalidad (que puede parecer incondicional) y las leyes que vienen a limitarla y condicionarla inscribiéndola en un derecho.» Derrida, J., Cosmopolites de tous les pays, encore un effort!, Paris, Editorial Galilée, 1997, 42-43. Traducido del francés.

24 Lazzeri, C. et Caillé, A., «La reconaissance aujourd'hui. Enjeux du concept», Revue du MAUSS N. ${ }^{\circ}$ 23: De la reconnaissance. Don, Identité et estime de soi, Paris, Centre national du Livre, 2004, 107.

25 Caillé, A., "Présentation», Revue du MAUSS, n. ${ }^{\circ}$ 23: De la reconnaissance. Don, Identité et estime de soi, Paris, Centre national du Livre, 2004, 20.

26 Ibid., 24.
27 Derrida, J., Dar el tiempo. I. La moneda falsa, Barcelona, Editorial Paidós, 1995, 155.

28 Ibid., 42.

${ }^{29}$ Ibid., 38.

30 Ibid., 37.

31 Véase aquí una equivalencia fundamental entre sacrificio y economía, cuestión que también aparece en Bataille. La pregunta que debe hacerse es, sin embargo, si Derrida, a diferencia de Bataille, logra romper con la lógica sacrificial/económica. El don, diría Bataille desnudando el «complejo» comunitario, siempre excesivo (agonístico), hace posible el pasaje de lo profano a lo sagrado, constituyéndose en el fundamento de la soberanía (la constitución de una superioridad a partir de un dar sin retorno). La soberanía, que sólo puede establecerse sobre el sacrificio del otro (extranjero, víctima maldita y sagrada), mantendría una íntima relación con lo sagrado: «El sacrificio es la pasión donde se encuentra la intimidad perdida de aquellos que componen el sistema de las obras comunes. La violencia es su principio, pero las obras la limitan en el tiempo y en el espacio; se subordina al cuidado de unir y conservar la cosa común (...)». Bataille, G., La parte maldita. Ensayo de economía general, Buenos Aires, Editorial Las Cuarenta, 2007, 67.

32 Derrida, J., Dar el tiempo, cit., 25.

33 «Y esto [el autorreconocimiento, la aprobación de sí mismo y la gratitud narcisista] se produce en cuanto hay un sujeto, en cuanto donador y donatario se constituyen como sujetos idénticos, identificables, capaces de identificarse (res) guardándose y nombrándose. Se trata, incluso, aquí, en este círculo, del movimiento de subjetivación, de la retención constitutiva del sujeto que se identifica consigo mismo. El devenir-sujeto cuenta entonces consigo mismo y entra como sujeto en el reino de lo calculable. Por eso, si hay don, el don ya no puede tener lugar entre unos sujetos que intercambian objetos, cosas o símbolos. La cuestión del don debería buscar, pues, su lugar antes de cualquier relación con el sujeto, antes de cualquier relación consigo mismo del sujeto, ya sea éste consciente o inconsciente. $\mathrm{Y}$ esto es lo que pasa con Heidegger cuando se remonta más acá de las determinaciones del ser como ente sustancial, sujeto u objeto. Cabría incluso decir que un sujeto como tal no da ni recibe jamás un don. Por el contrario, se constituye con vistas a dominar, por medio del cálculo y del intercambio, el manejo de esa hybris o de esa imposibilidad que se anuncia en la promesa del don. Allí donde hay sujeto y objeto, el don queda excluido. Un sujeto no dará nunca un objeto a otro sujeto. Pero el sujeto y el objeto son efectos fijos del don: trabas del don. A la velocidad nula o infinita del círculo.» Derrida, J. Ibid, 32.

34 Ibid., 133.

35 En La parte maldita, Bataille sostiene que el don tiene un efecto jerarquizante fundamental: gastando sin reservas las personas se elevan a su rango. Pero lo que hace que los hombres se metan en este «movi- 
miento frenético de gasto» es el sacrificio al que da lugar el don. El gasto coloca a aquel que lo hace en un ámbito de reconocimiento instintivo de valor y majestad, arcano de identidad y soberanía frente a los demás. El sacrificio implicado en el don se constituye en el fundamento de la soberanía: de ahí la productividad para la lógica soberana (deseo de gloria existente en nosotros, que no es otro que el deseo de lo sagrado) de hacer de la excepción sobre el otro, de su sacrificio, la regla de todas las reglas.

36 Aparece aquí del dilema rousseaniano: la extrema libertad (interna en la mullida clausura) se toca con la extrema esclavitud (del otro, de aquel que se encuentra más allá de la propia casa). Dilema que también aparece en la Política de Aristóteles respecto del bien del ciudadano (siempre relativo al ethos de comunidad) y el bien del hombre (sin medida, sin referencia, en la extrema soledad de la decisión).

37 Derrida, Jacques, La Hospitalidad, Buenos Aires, Editorial de la Flor, 2000, 68-69.

38 Ibid., 87.

39 Ibid., 70.

40 «La guerra es otra experiencia de la muerte dada [yo doy (la) muerte al enemigo y doy la mía en el sacrificio de "morir por la patria"].» Ibíd., 17.

41 Ibid, 87.

42 Derrida, J., Dar el tiempo, cit., 133.

43 «Porque, a fin de cuentas, el desbordamiento del círculo mediante el don - si lo hay - no conduce a una mera exterioridad inefable, trascendente y sin relación. Dicha exterioridad es la que pone en marcha el círculo, ella es la que da movimiento a la economía. Es ella la que (compro)mete en el círculo y la que le hace dar vueltas. Si es preciso rendir cuentas (a la ciencia, a la razón, a la filosofía, a la economía del sentido) de los efectos de círculo en los que se anula un don, dicho rendir-cuentas requiere que se tenga en cuenta lo que, no perteneciendo simplemente al círculo (compro)mete en él y lo pone en movimiento.» Ibid., 38-39.

44 «El acontecimiento y el don, el acontecimiento como don, el don como acontecimiento, deben ser irruptivos, inmotivados - por ejemplo, desinteresados-. Al ser decisivos, deben desgarrar la trama, interrumpir la continuidad de un relato que, no obstante, requieren, deben perturbar el orden de las causalidades: en un instante.» Ibid., 122.
45 Ibid., 144.

46 «La "buena amistad" supone la desproporción. Exige una cierta ruptura de reciprocidad o de igualdad, la interrupción también de toda fusión o confusión entre tú y yo. (...) La buena amistad nace de la desproporción: cuando se estima o respeta al otro más que a sí mismo. (...) Ésta nos exige abstenernos "sabiamente", prudentemente de toda confusión, de toda permutación entre las singularidades del tú y del yo. He aquí que se anuncia la comunidad sin comunidad de los pensadores por venir.» «Una lógica del don sustrae así la amistad a su interpretación filosófica (...) la llama a la no-reciprocidad, a la disimetría o a la desproporción, al no-retorno en la hospitalidad ofrecida o recibida, en suma a la irreductible prelación del otro. A su deferencia.» Derrida, J., Adiós a... cit., 81, 82.

47 «(...) la diferencia, una de las sutiles diferencias a veces imperceptible entre el extranjero y el otro absoluto es que este último puede no tener nombre ni apellido; la hospitalidad absoluta o incondicional que quisiera ofrecerle supone una ruptura con la hospitalidad en el sentido habitual, con la hospitalidad condicional, con el derecho o el pacto de hospitalidad. (...) la hospitalidad absoluta exige que yo abra mi casa y que dé no sólo al extranjero (provisto de un apellido, de un estatuto social de extranjero) sino al otro absoluto, desconocido, anónimo, y que le dé lugar, lo deje venir, lo deje llegar, y tener lugar en el lugar que le ofrezco, sin pedirle ni reciprocidad (la entrada en un pacto) ni siquiera su nombre.» Derrida, J., La Hospitalidad, cit., 30-31.

48 «¿Cómo puede el otro ver en mí, en lo más secreto de mí, sin que yo mismo vea ahí y sin que yo pueda verlo en mí? Y si el secreto de mí en cuanto que no se entrega más que al otro, a cualquier/radicalmente otro, a Dios, si se quiere, es un secreto sobre el que no reflexionaré jamás, que no viviré, ni conoceré, ni me reapropiaré nunca como mío.» Derrida, J., Dar la muerte, Barcelona, Editorial Paidós, 2000, 90.

49 «La huella de esta visitación desune y perturba, como puede ocurrir en el caso de una visita imprevista, inesperada, temida, esperada más allá de la espera, sin duda, tal vez como una visita mesiánica, pero, antes que nada, porque su pasado, la "pasada del huésped", excede toda representación anamnésica; nunca pertenecerá a la memoria de un presente pasado.» Ibid., 86. 